\title{
SYNTHESIS AND STRUCTURAL PROPERTIES OF CHITIN/CLAY BIO-NANOCOMPOSITES
}

\author{
NEVIN ÇANKAYA \\ Department of Chemistry, Usak University, Usak, Turkey \\ \Corresponding author: nevin.cankaya@usak.edu.tr,nevincankaya@hotmail.com
}

Received June 4, 2020

Chitin, which is composed of 2-acetamido-2-deoxy-D-glucopyranose (N-acetyl-D-glucosamine) units linked by $\beta$-(1,4) linkage, makes up the cell walls of fungi, the exoskeletons of arthropods, such as crustaceans (e.g., crabs, lobsters and shrimps) and insects, the radulae of mollusks, and the beaks of cephalopods, including squid and octopuses. Both chitin and clay are sustainable materials, as they are low cost, biodegradable and readily available. That is why, in this study, sodium montmorillonite $(\mathrm{CNa})$ nanoclay and 1-140 $(\mathrm{C} 15 \mathrm{~A})$ organo-nanoclay were used as nanofiller support in the preparation of chitin/clay bio-nanocomposites. Trichloroacetic acid was used to dissolve the chitin and to disperse the clay in the chitin solution. Chitin/CNa and chitin/C15A bio-nanocomposites were synthesized by the solution-induced intercalation method. The effect of the nanofiller on the bio-nanocomposite was investigated by varying the loading rates as follows: 1,3 and $5 \%$ by weight. The composites were characterized by FT-IR, XRD and SEM methods. The XRD patterns and SEM images showed that the clay dispersion in the chitin biopolymer matrix presented an exfoliated structure. It was noted that neither the nanoclay nor the organo-nanoclay used in the synthesis of the bio-composites affected the formation of the exfoliated structure. This result can be attributed to the use of a low amount of clay. These newly synthesized bio-composites, which are environmentally friendly and sustainable, can find application in many different areas in the future.

Keywords: chitin, bio-nanocomposite, biodegradable polymers, montmorillonite, organoclays, exfoliated

\section{INTRODUCTION}

The development and application of biopolymers has received increasing interest due to their good biocompatibility, biodegradability and availability. Chitin is one particular longchain biopolymer composed of $\mathrm{N}$-acetyl glucosamine. It is available from a number of natural sources. ${ }^{1}$ It is found in the cuticles of insects and the shells of crustaceans, being one of the most abundant biopolymers in nature after cellulose. ${ }^{2}$ It has a very similar structure to that of cellulose, except that it has an acetyl group instead of the hydroxyl group in cellulose. ${ }^{1}$ Its water insolubility is caused by the strong interand intra-molecular hydrogen bonds between its polymer chains. ${ }^{3,4}$

The healthcare industry widely utilizes chitin and chitosan, thanks to their biofriendliness and availability. However, this is not the only domain where chitin and chitosan can find application. Due to their above-mentioned properties, their use in materials science can also be of interest. However, an important drawback of chitin is that it does not dissolve in common solvents, and because of this, its use is limited. ${ }^{5}$ Chitin is soluble in strong acids, such as di/trichloroacetic acid, and polar solvents, such as hexafluoroisopropyl alcohol, lithium chloride/dimethylacetamide mixtures. ${ }^{6,7}$ A method has been developed to dissolve chitin by freezing/thawing in $\mathrm{NaCl} /$ urea aqueous solution. ${ }^{5,8}$

Polymer nanocomposites are multi-phase materials, consisting of a polymer matrix and nanofillers. Compared to homopolymers and traditional polymer composites, they exhibit distinctive physical properties, even with low loading of nanofillers. One way to improve the thermal and mechanical properties of polymers is to prepare nanocomposites or organic-inorganic hybrid materials by providing equal distribution of the nanofiller in a polymer matrix. ${ }^{9}$ The most common, easy to find and the cheapest filling/support material used for this purpose in polymer composites is clay. Thanks to clay fillers Cellulose Chem. Technol., 55 (5-6), 659-665(2021) 
added to the polymer, the mechanical, thermal and barrier properties are generally strengthened. ${ }^{10}$

However, a strong aggregation tendency of the clay filler can prevent from obtaining homogeneous dispersions. Therefore, the most important condition is to increase the physical properties of the nanoclay in the polymer matrix. ${ }^{11}$ For this purpose, the amount and the type of the nanofiller used are very important. ${ }^{12}$ High levels of clay fillers ( $>50 \%$ by weight) increase the product density and may cause the properties of the material to deteriorate because of the interface mismatch between the filler and the organic matrix. Nanocomposites are polymers filled with particles whose at least one dimension (such as length, width, or thickness) is within the nanometer range. Therefore, higher interface interaction between the nanoparticles and the polymer matrix is expected. For achieving this interaction, lower ratios of the filler material should be used. The most successful results have been obtained for composite materials with low filler content $(<10 \%$ by weight $) .{ }^{13-16}$

Clay layers can form intercalated type or exfoliated type structures within the polymer matrix. An intercalated structure occurs when high clay loadings are used, or when polymerization does not occur between the clay layers if they are not separated sufficiently during polymerization. An exfoliated structure usually occurs at low clay rates ( $1-15 \%)$ and by separating the clay layers as much as possible. ${ }^{16}$

In this study, $\mathrm{Na}^{+}$montmorillonite and organoclay 1-140 have been used as nanofiller support clays to synthesize chitin/clay bionanocomposites. Low nanofiller amounts were used for each type of clay $(1,3$ and $5 \%$ by weight). Then, the chemical structure and physical properties of the synthesized bionanocomposites were characterized by FT-IR, XRD and SEM analyses. In previously reported studies, biopolymer/clay composites, except those based on the chitin biopolymer, were synthesized with low clay ratios. Chitin biopolymer/clay (different types of clays) composites/blends/hydrogels have also been developed for different applications. ${ }^{6,715}$ Unlike other reported studies, the present work aimed to achieve the synthesis of chitin composites with the addition of low clay content, which has not been encountered in the literature published so far. Chitin/clay composite hydrogel systems, incorporating high amounts of clay, have been investigated as bio-adsorbents to remove dyes, heavy metal ions and oils from polluted water, due to their high swelling capacity. ${ }^{1,15}$

\section{EXPERIMENTAL Materials}

Powder chitin, extracted from shrimp shells, and trichloroacetic acid were purchased from SigmaAldrich. To prepare the solutions, double-distilled water was used. Two different nanoclays, namely, sodium montmorillonite $(\mathrm{CNa})$ and organo-nanoclay 1140 (C15A), were procured from Esan-Eczacıbaş1. $\mathrm{CNa}$ is a bentonite clay, modified with $\mathrm{Na}^{+}$to increase the cation content, which has a particle size $<63 \mu \mathrm{m}$. C15A organo-nanoclay, belonging to the montmorillonite group, was modified with dimethyl, dihydrogenated tallow, and quaternary ammonium cation, and had a particle size $<20 \mu \mathrm{m}$ (with tallow of $\sim 65 \% \mathrm{C} 18, \sim 30 \% \mathrm{C} 16, \sim 5 \% \mathrm{C} 14)$. Long-chain alkyl groups (tallow) are used extensively in order to expand the interlayer spacing. ${ }^{12,13,16}$

\section{Preparation of chitin/clay bio-nanocomposites}

Chitin/clay bio-nanocomposites were synthesized by the solution blending method. An amount of $3 \mathrm{~g}$ of chitin was dissolved in a trichloroacetic acid solution. $1 \%, 3 \%$ or $5 \%$ by weight of $\mathrm{CNa}$ nanoclay and of C15A organo-nanoclay (used separately) were added to dilute trichloroacetic acid and allowed to swell under stirring with a magnetic stirrer at $60{ }^{\circ} \mathrm{C}$ for 24 hours. Each clay suspension was added slowly to a solution of 3 grams of chitin and continuously mixed at $1000 \mathrm{rpm}$ for 24 hours at $60{ }^{\circ} \mathrm{C}$. The resulting solution was allowed to dry for days and was subsequently washed several times with distilled water. ${ }^{6,7,16}$ The bionanocomposites synthesized with the two different types of clay, in three different amounts, were then dried again in the oven, pestled and sifted through a 10 micron sieve.

\section{Instrumental measurements}

The IR spectra of all the samples were recorded with a PerkinElmer Spectrum Two (UATR) IR spectrometer. XRD patterns were attained using a Bruker Axs D8 Advance diffractometer. SEM micrographs were obtained on a Zeiss Evo LS 10 at 25 $\mathrm{kV}$.

\section{RESULTS AND DISCUSSION FT-IR spectroscopy}

The FT-IR technique is the first spectroscopic method used to identify functional groups within a molecule. The spectrum of chitin displayed characteristic bands at $3440 \mathrm{~cm}^{-1}(\mathrm{O}-\mathrm{H}$ stretch $)$, $3260 \mathrm{~cm}^{-1} \quad(\mathrm{~N}-\mathrm{H}$ stretch $), 2880 \mathrm{~cm}^{-1} \quad(\mathrm{~N}-\mathrm{H}$ symmetric stretch $), \quad 1654 \mathrm{~cm}^{-1} \quad(\mathrm{C}=\mathrm{O}$ amide stretch), $1615 \mathrm{~cm}^{-1}$ (N-H bending), $1552 \mathrm{~cm}^{-1}(\mathrm{~N}-$ 
C stretch), $1375 \mathrm{~cm}^{-1}$ (C-H bending vibration), 1050 and $1015 \mathrm{~cm}^{-1}(\mathrm{C}-\mathrm{O}$ asymmetric and symmetric vibration). ${ }^{7,17}$

The characteristic nature of clay lies in its containing molecules such as $\mathrm{SiO}_{2}, \mathrm{Al}_{2} \mathrm{O}_{3}$ and $\mathrm{MgO}$. The FT-IR spectra of the $\mathrm{CNa}$ clay showed that the $\mathrm{O}-\mathrm{H}$ stretch and bending peaked at 3624 and $1450 \mathrm{~cm}^{-1}$, respectively; $\mathrm{Si}-\mathrm{O}$ stretch and bending peaked at 1010 and $514 \mathrm{~cm}^{-1}$, respectively; $\mathrm{Al}-\mathrm{OH}$ and $\mathrm{Mg}-\mathrm{O}$ vibration peaked at 913 and $475 \mathrm{~cm}^{-1}$, respectively. ${ }^{13,16,18}$ These mentioned peaks were also observed for the $\mathrm{C} 15 \mathrm{~A}$ organoclay. The following peaks due to the dimethyl dialkyl chain and quaternary ammonium chloride structures, which are the modifier structures in clay, were observed: aliphatic $(\mathrm{N}$ $\left.\mathrm{CH}_{3}\right)$ and aliphatic $\left(\mathrm{CH}_{2}\right)$ vibration at 2840 and $1465 \mathrm{~cm}^{-1}$, respectively; aromatic $(\mathrm{C}=\mathrm{C})$ stretching vibration at $1644 \mathrm{~cm}^{-1}$, asymmetric and symmetric $(\mathrm{C}-\mathrm{H})$ stretching vibration at $2920 \mathrm{~cm}^{-}$ 116,18

As regards the FT-IR spectra of the chitin/clay bio-nanocomposites, the $3440(\mathrm{O}-\mathrm{H})$ and 3260 $\mathrm{cm}^{-1}(\mathrm{~N}-\mathrm{H})$ stretch peaks, coming from chitin, and the $3624 \mathrm{~cm}^{-1}(\mathrm{O}-\mathrm{H})$ stretch peak, coming from clay, are combined and observed as a wide peak at $\sim 3260 \mathrm{~cm}^{-1}$. The $1025 \mathrm{~cm}^{-1}$ peak of chitin overlapped with the $\sim 1005 \mathrm{~cm}^{-1}$ (Si-O stretch) peak of clay.

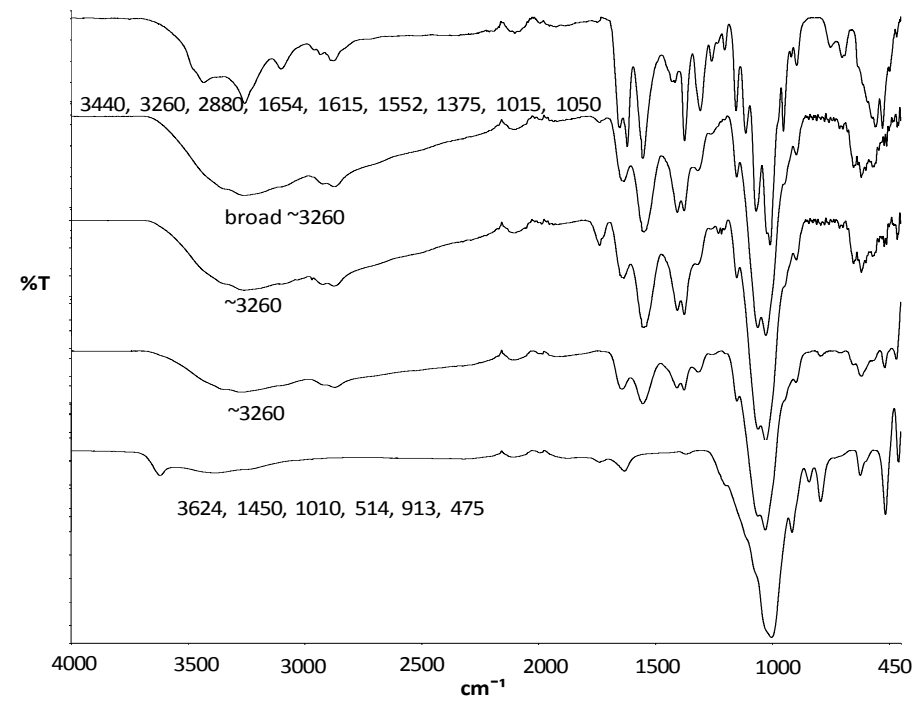

Figure 1: FT-IR spectra of chitin, $\mathrm{Ct} / 1 \% \mathrm{CNa}, \mathrm{Ct} / 3 \% \mathrm{CNa}, \mathrm{Ct} / 5 \% \mathrm{CNa}$ and $\mathrm{CNa}$ (from top to bottom)

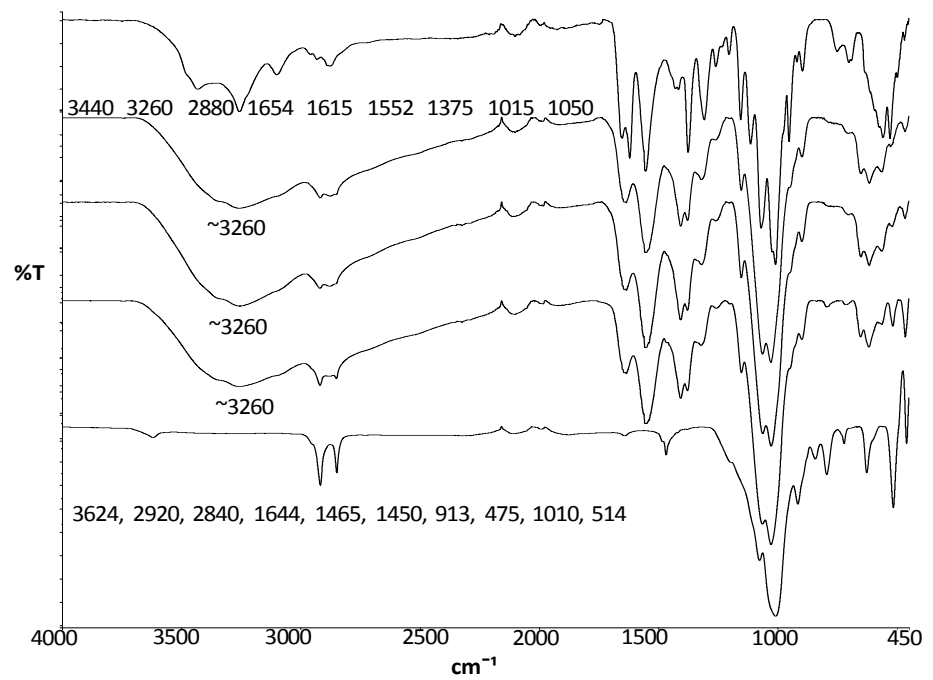

Figure 2: FT-IR spectra of chitin, $\mathrm{Ct} / 1 \% \mathrm{C} 15 \mathrm{~A}, \mathrm{Ct} / 3 \% \mathrm{C} 15 \mathrm{~A}, \mathrm{Ct} / 5 \% \mathrm{C} 15 \mathrm{~A}, \mathrm{C} 15 \mathrm{~A}$ (from top to bottom) 


\section{NEVIN ÇANKAYA}

These peaks can be observed as the clay concentration increases. Figures 1 and 2 show FTIR spectra of the chitin, the clays and the chitin/clay bio-nanocomposites, comparatively.

\section{Morphological study using XRD measurements}

XRD analysis is a technique used to characterize layered structure types (intercalated or exfoliated) of polymer/clay nanocomposites. In the literature, the characteristic peaks of chitin are about $20^{\circ}(\mathrm{d}=0.44 \mathrm{~nm}) .{ }^{19-21}$ The diffraction angle of the CNa clay $2 \theta=6.5^{\circ}, 20^{\circ}, 22^{\circ}$ (basal spacing $\mathrm{d}=1.36,0.44,0.40 \mathrm{~nm}$ ); the diffraction angle of the $\mathrm{C} 15 \mathrm{~A}$ organoclay was read as $2 \theta=3^{\circ}, 4.8^{\circ}$, $20^{\circ}, 22^{\circ}(\mathrm{d}=1.47,1.64,0.44,0.40 \mathrm{~nm}){ }^{16}$ That means the basal rate of the modified clay is largely affected by the volume of the substituent of the intercalating agent and by the long alkyl chain. Thus, shifts to lower theta values occur upon modification.
Considering the chitin/ $\mathrm{CNa}$ and chitin/C15A bio-nanocomposites, their XRD patterns indicate that the chitin is dispersed in layers and an exfoliated structure is formed. The dispersion of the polymer between the silicate layers of the clay causes unclear XRD peaks in composites. The absence of distinctive clear peaks in composite materials indicates that the polymer can penetrate between the clay layers, so the clay layers cannot give a clear XRD signal. As a result, some irregular peaks may occur. ${ }^{16,22-25}$ Therefore, the clay/organoclay-containing chitin bionanocomposites we synthesized can be regarded as an exfoliated structure. Also, the small peaks $\left(6.5^{\circ}, 4.8^{\circ}\right.$ and $\left.5.4^{\circ}\right)$ remarked in the clays are not observed in the bio-nanocomposites. These results provide evidence that the clay/organoclay is dispersed in the chitin biopolymer matrix, as an exfoliated structure. The XRD patterns of the chitin, organoclay/clay, and their bionanocomposites are displayed in Figures 3 and 4, respectively.

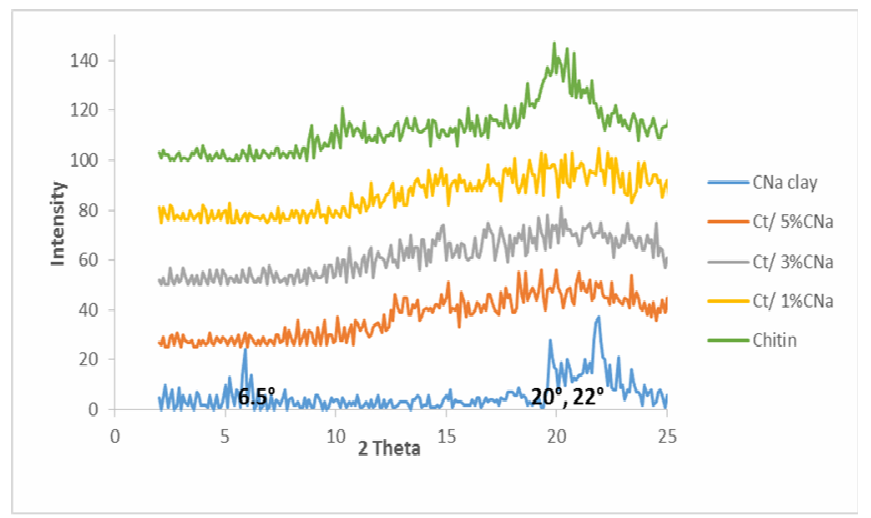

Figure 3: XRD patterns of chitin, $\mathrm{CNa}$ and their bio-nanocomposites

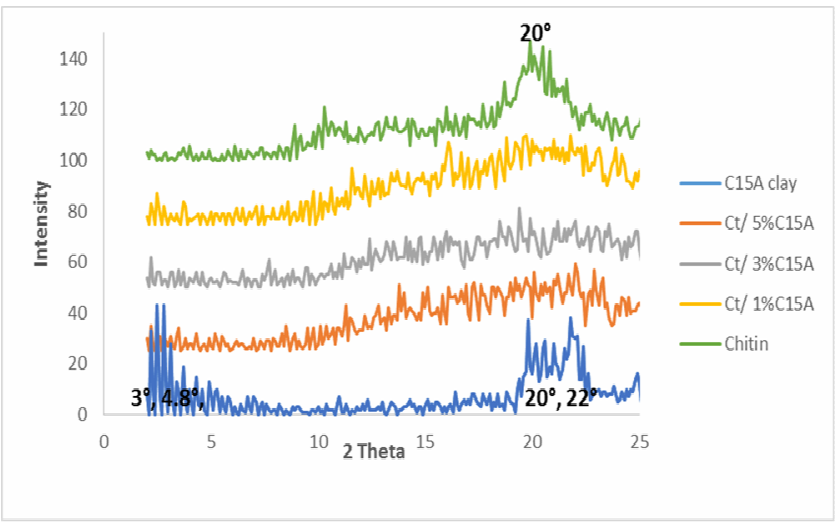

Figure 4: XRD patterns of chitin, C15A clay, and their bio-nanocomposites 


\section{Morphological study by SEM}

SEM analysis was performed to observe the distribution of the chitin biopolymer, the clay species and the synthesized bio-nanocomposites. Figures 5 and 6 show the SEM images of the chitin/clay and chitin/organoclay bionanocomposites. In addition to the XRD results, SEM micrographs also demonstrate that the bio- nanocomposites exhibit exfoliation behavior. In the SEM micrographs given at $1 \mu \mathrm{m}$ size, no clear clay clusters are observed, indicating that the biopolymer of chitin can be homogeneously distributed between the silicate layers of the clay. This distribution continues even when the amount of clay increases and/or the clay type changes, demonstrating an exfoliating structure.
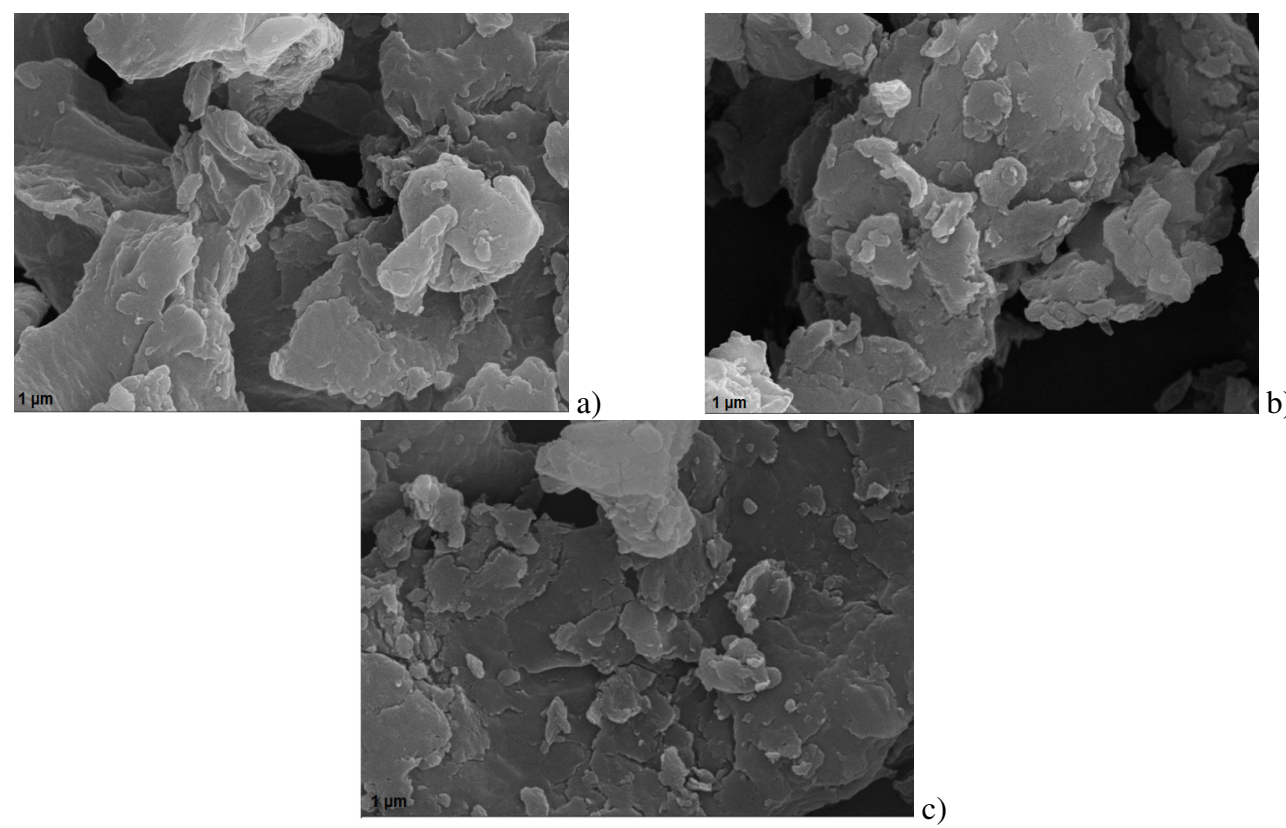

b)

c)

Figure 5: SEM images of $\mathrm{Ct} / 1 \% \mathrm{CNa}(\mathrm{a}), \mathrm{Ct} / 3 \% \mathrm{CNa}$ (b) and $\mathrm{Ct} / 5 \% \mathrm{CNa}(\mathrm{c})$, respectively
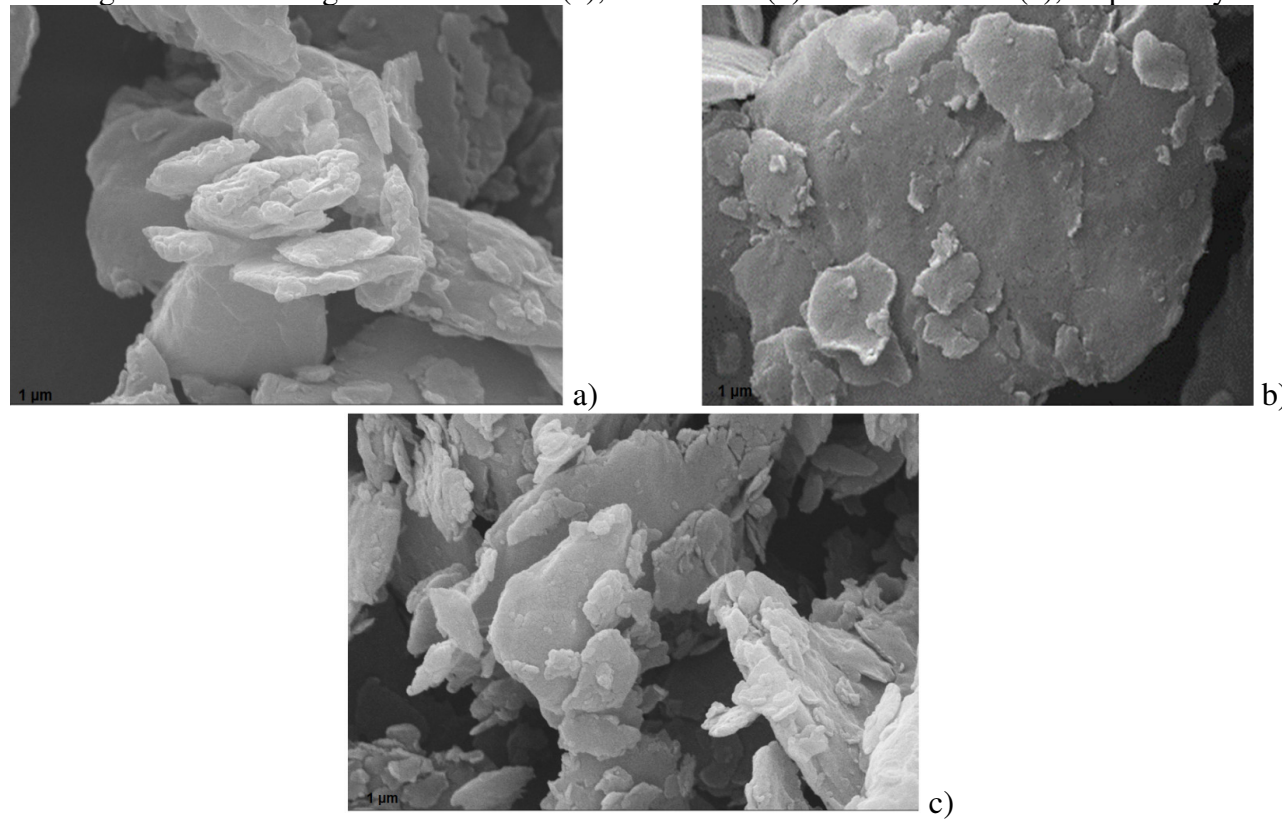

Figure 6: SEM images of $\mathrm{Ct} / 1 \% \mathrm{C} 15 \mathrm{~A}, \mathrm{Ct} / 3 \% \mathrm{C} 15 \mathrm{~A}, \mathrm{Ct} / 5 \% \mathrm{C} 15 \mathrm{~A}$, respectively 
Also, SEM micrographs indicate that the particle sizes of the composite are close to each other and, when examined carefully, the increase in the clay ratio causes the particle sizes to increase partially.

In the literature, it is stated that an exfoliated structure is formed in both organoclay and claycontaining nanocomposites with the addition of a small amount of clay. ${ }^{12,13,16,23,24}$ In our study, polymer matrices were distributed properly between the clay layers and an exfoliated structure was formed with the addition of both the nanoclay or the organoclay. As a result, the analysis results we have obtained are quite compatible with those reported in the literature. ${ }^{12-}$ 25

\section{CONCLUSION}

Chitin/clay and chitin/organoclay bionanocomposites were successfully prepared by the solution mixing technique. For this purpose, clay species $\mathrm{CNa}$ nanoclay and $\mathrm{C} 15 \mathrm{~A}$ organonanoclay were used in amounts of 1,3 and $5 \%$ by weight. FT-IR, XRD and SEM were used to characterize the materials obtained. These characterization methods demonstrated the interaction between the clay/organoclay molecules and the chitin biopolymer, proving that chitin can be evenly distributed among clay layers. The XRD patterns and SEM images indicated that both chitin/clay and chitin/organoclay bio-nanocomposites have exfoliated structure, in other words, the type of clay used - the organo-nanoclay or the nanoclay did not affect the results. Since chitin and clay are low-cost, biodegradable and easily accessible in nature, the newly synthesized bio-composites will be environmentally friendly materials. The chitin/clay bio-composites developed can find a vast range of applications, from wastewater treatment, heat or sound insulators, to biomaterials to be used in biomedical areas and in tissue engineering. It is expected that the paper will contribute to broadening the field of application of these materials. Our team specifically plans to use these synthesized lowcost bio-nanocomposites for the removal of dyes and metal ions from wastewater.

ACKNOWLEDGEMENT: The authors would like to thank the Usak University Research Fund for financial support of this work (2012/MF006).

\section{REFERENCES}

1 G. Akkaya, İ. Uzun and F. Güzel, Desalination, 249, 1115

(2009),

https://doi.org/10.1016/j.desal.2009.05.014

2 F. S. Kittur, K. V. H. Prashanth, K. U Sankar and R. N. Tharanathan, Carbohyd. Polym., 49, 185 (2002), http://ir.cftri.com/id/eprint/3375

3 S. B. Murray and A. C. Neville, Int. J. Biol. Macromol., $\quad 20, \quad 123 \quad$ (1997), https://doi.org/10.1016/S0141-8130(96)01151-8

4 M. Sugimoto, M. Morimoto, H. Sashiwa, H. Saimoto and Y. Shigemasa, Carbohyd. Polym., 36, 49 (1998), https://doi.org/10.1016/S0144-8617(97)00235$\mathrm{X}$

5 M. Liu, Y. Zhang, J. Li and C. Zhou, Int. J. Biol. Macromol., $\quad \mathbf{5 8 ,} \quad 23 \quad$ (2013), https://doi.org/10.1016/j.ijbiomac.2013.03.042

6 D. Saravana, T. Gomathi and P. N. Sudha, Int. J. Chem. Anal. Sci., 2, $1265 \quad$ (2011), https://citeseerx.ist.psu.edu/viewdoc/download?doi=10 .1.1.736.9027\&rep=rep1\&type $=$ pdf

7 D. Saravanan and P. N. Sudha, Elixir Applied Chemistry, 44, $7374 \quad$ (2012), https://www.elixirpublishers.com/articles/1350887605 -44\%20(2012)\%207374-7377.pdf

C. Chang, S. Chen and L. Zhang, J. Mater. Chem. A, 21, 3865 (2011), https://doi.org/10.1039/C0JM03075A

9 C. Chang, N. Peng, M. He, Y. Teramoto, Y. Nishio et al., Carbohyd. Polym., 91, 7 (2012), https://doi.org/10.1016/j.carbpol.2012.07.070

10 J. B. Zeng, Y. S. He, S. L. Li and Y. Z. Wang, Biomacromolecules, $\quad \mathbf{1 3}, \quad 1 \quad$ (2012), https://doi.org/10.1021/bm201564a

11 D. LeCorre, J. Bras and A. Dufresne, Biomacromolecules, $11, \quad 1139 \quad$ (2010), https://doi.org/10.1021/bm901428y

12 Y. Xu, X. Ren and M. A. Hanna, J. Appl. Polym. Sci., 99, 1684 https://doi.org/10.1002/app.22664

13 O. I. H. Dimitry, N. A. Mansour and A. L. G. Saad, Int. J. Chem. Mol. Eng., 10, 283 (2016), https://doi.org/10.5281/zenodo.1128135

14 N. Cankaya and Ö. Sökmen, Journal of Polytechnic, 20, 663 (2017), https://doi.org/10.2339/politeknik.339394

15 Z. Zhang and L. A. Lucia, J. Mater. Sci., 56, 3600 (2021), https://doi.org/10.1007/s10853-020-05464-y

16 N. Cankaya and R. Sahin, Cellulose Chem. Technol., $\quad 53, \quad 537$ (2019), https://doi.org/10.35812/CelluloseChemTechnol.2019. 53.54

17 S. Ifuku, R. Nomura, M. Morimoto and $\mathrm{H}$. Saimoto, Materials, 4, $1417 \quad$ (2011), https://doi.org/10.3390/ma4081417

18 C. Paluszkiewicz, E. Stodolak, M. Hasika and M. Blazewicz, Spectrochim. Acta Part A: Mol. Biomol. 
Spectrosc., 79 ,

784

(2011), https://doi.org/10.1016/j.saa.2010.08.053

19 M. Kaya, Y. S. Cakmak, T. Baran and A. Ozusaglam, Biotechnol. Bioprocess Eng., 19, 58 (2014), https://doi.org/10.1007/s12257-013-0488-9

20 B. Duan, C. Chang, B. Ding, J. Cai, M. Xu et al., J. Mater. Chem. A, 1, 1867 (2013), https://doi.org/10.1039/C2TA00068G

21 J. Kumirska, M. Czerwicka, Z. Kaczyński, A. Bychowska, K. Brzozowski et al., Mar. Drugs, 8, 1567 (2010), https://doi.org/10.3390/md8051567
22 A. Kurt and M. Koca, J. Eng. Res., 4, 46 (2016), https://doi.org/10.36909

23 A. Kurt and M. Koca, Arab. J. Sci. Eng., 40, 2975 (2015), https://doi.org/10.1007/s13369-015-1738-2

24 N. Çankaya, Sigma Journal of Engineering and Natural Sciences, 38, $1113 \quad$ (2020), https://eds.yildiz.edu.tr/sigma/Articles

25 N. Çankaya, B. Vurgun and S. Yalçın, Polym. Bull., (2021), https://doi.org/10.1007/s00289-02003449-0 